This is the author's version of a work that was published in the following source:

Paetz, A.-G.; Kaschub, T.; Jochem, P.;

Fichtner, W. (2013).

\title{
Load-shifting potentials in households including electric mobility: A comparison of user behaviour with modelling results .
}

10th International Conference on the European Energy Market, EEM 2013, Stockholm, Sweden, 27th - 31st May 2013, Art.Nr. 6607324, IEEE, Piscataway (NJ). doi:10.1109/EEM.2013.6607324

Please note: Copyright is owned by the author(s) and / or the publisher. The commercial use of this copy is not allowed. 


\title{
Load-Shifting Potentials in Households Including Electric Mobility - a Comparison of User Behaviour with Modelling Results
}

\author{
Alexandra-Gwyn Paetz, Thomas Kaschub, Patrick Jochem, and Wolf Fichtner \\ Karlsruhe Institute of Technology (KIT) \\ Chair of Energy Economics \\ Karlsruhe, Germany \\ paetz@kit.edu
}

\begin{abstract}
This paper analyses the potential of demand response (DR) in households considering smart appliances and electric vehicles (EV). A model-based analysis allows calculating the technically possible and economically feasible load-shifting potential, while behavioral analysis enables estimating the potential of the model with real-user experiences in a smart home laboratory. The modeling results show that $\mathrm{EV}$ are especially suitable for load-shifting activities due to their long parking hours and high power as well as energy demand. Together with smart household appliances (dishwasher, washing machine, tumble dryer) most of the electricity demand can be technically shifted in time. The experimental results strongly support the modeling results - especially with demand automation. However, user acceptance of load-shifting activities depends largely on the design of direct real-time feedback, the comprehensiveness of electricity pricing, and the customerfriendliness of smart household appliances.
\end{abstract}

Index Terms - consumer behavior, demand response, electric vehicles, load management, smart homes.

\section{INTRODUCTION}

The aim of reducing greenhouse gas emissions by $80 \%$ in Germany by 2050 with respect to 1990 [1] causes major changes in the energy sector: electricity is increasingly generated from renewable resources, that are partly volatile, hardly controllable and to some extent generated decentralized. This challenge might rise with an increasing number of electric vehicles (EV). Their electricity demand, especially in the evening hours, is going to increase the already existing peak-load of households. This issue is widely discussed in the literature - especially for high market penetration of EV [2].

Demand Response (DR) can be implemented by offering households a price incentive to demand electricity at a different time - e.g. when renewable supply is available or load is low (dynamic pricing - for a detailed description of dynamic pricing cf. [3]). The concept of DR seems promising,

We gratefully acknowledge funding by the German Federal Ministry of Economics and Technology as part of the projects MeRegioMobil and iZeus. especially when the demand is not critical in time - thus offers high flexibility and potential to be shifted in time. Theoretically this is the case for charging the battery of EV due to their long parking hours and high energy demand. In principle the use of the washing machine, the tumble dryer and the dishwasher can also be shifted in time ${ }^{1}$.

However, it is not clear how effective DR is. Only few households are confronted with dynamic pricing and at the same time only few households own EV or smart household appliances that could react automatically to dynamic pricing.

Thus a two-step approach has been chosen to analyze the effectiveness of DR with dynamic pricing. First, an optimization model (DS-Opt + ) has been developed in order to quantify the effects of load-shifting under the precondition of homo oeconomicus that reacts with high elasticity to minor changes in prices. Second, experimental studies in an energy smart home laboratory (ESHL) have been conducted with real users in order to observe how load-shifting can be realized under field conditions.

The paper is structured in five sections. In the following we give a short literature review in order to integrate our research question. Section three explains the methodological approach. We present our result in section four before discussing them in the final part of the paper.

${ }^{1}$ Other appliances, such as freezers, could be of interest as well, but are not in focus of this study, as they hardly require human interaction. 


\section{OUTLINE OF LITERATURE}

There are several streams of research dealing with DR. The majority of work focuses on the conceptual side of DR and analyzes its benefits (cf. [4]). Computer and IT scientists focus on the development of algorithms to manage energy flows and appliances within households (cf. [5]). Energy economists analyze the effects of DR with different modeling approaches (cf. [6]) either on an aggregated level (cf. [7]) or on a more detailed level focusing on specific regions, cities, neighborhoods or even just single households (cf. [8]).

Gottwalt et al. [9] show with their simulation model that responsive loads of household appliances can lead to higher peaks, but at other times of a day. This is even truer for the loads of EV-charging (cf. [10], [11], [12], [13]). Thus sophisticated DR-strategies are required (cf. [14]; [15]; [16]). Kaschub et al. [17] show with an optimization model that several types of dynamic pricing models can be used for different load objectives ${ }^{2}$ : While time-of-use (TOU) as well as real-time pricing (RTP) can be used for load-building, pricing models with load-limits are effective for load-harmonization (clipping and filling).

Several field-tests have been conducted with households that were equipped with a certain amount of technology (usually smart meters and feedback devices) and offered some kind of dynamic pricing model. Most of them are accompanied by social scientist that look at the behavioral effects of DR and analyze the acceptance of the households. These trials show that dynamic pricing can be indeed effective for DR - however it is not clear to which extent. A metareview by Stromback et al. [18] reports load-shifting effects from $5 \%$ to $16 \%$ - not knowing how stable these effects can be over time. This could be critical as usual residential consumers do not seem to be open to behavioral changes in daily routines (cf. [19]). Consumers therefore indicate high acceptance of smart appliances and perceive home automation systems positively. However, not many quantitative results on the impact of smart appliances in residential homes are reported so far. A field-test in California with smart thermostats reports a reduction of peak-consumption by $27 \%$ [20].

The real-user experiences are even less clear for EVcharging. A study with non-users indicates that it is especially difficult to generate acceptance for shifting the charging process (smart charging), as it is perceived as too restrictive in the context of EV, which are seen as symbols for spontaneity [21]. During a German field test with battery electric cars, dynamic pricing had been introduced and had indeed little to no effects on battery charging - even though all participants had reported their willingness to charge "green" electricity and ride without emissions [22]. A survey with participants of a field test with electric scooters (e-scooters) might offer an explanation: the willingness to shift battery-charging depends on cost-saving potentials that are low due to comparably low charging fees [23]. Participants of both field-tests reported

${ }^{2}$ For classification of load-objectives cf. [20] high acceptance for automatic charging solutions that would allow more convenience in smart charging.

Thus model-based research shows that DR can be effective in shifting the demand of both household appliances as well as EV-charging. However, an integrated view on future households that will be equipped with both smart household appliances and EV is missing. That is also the case for fieldtrials: no real-user-experiences of DR in the context of both household appliances and EV are reported so far.

This is remarkable as we expect further development and market penetration of smart household technologies as well as EV. Therefore it is crucial to analyze how this development will affect load-responsiveness with regard to a more volatile supply - in theory and practice.

\section{METHODOLOGY}

In order to answer the research question outlined above we address both aspects (theory and practice) by using (i) a model-based as well as an (ii) experimental approach. While the model-based analysis (i) allows us to calculate the technically possible and economically feasible load-shifting potential by assuming rational behavior in households (homo oeconomicus), behavioral analysis (ii) enables us to evaluate the techno-economical potential of the model with real-user experiences from a laboratory setting.

\section{A. Demand-Side Optimization plus Electric Mobility (DS- \\ $\mathrm{Opt}^{+}$)}

Based on mobility statistics [24] we modeled 500 representative households of a neighborhood in the outskirts of a large city, as market penetration is expected in these areas first [25]. All households optimize their electricity demand minimizing energy costs (cf. equation 1). Costsaving potentials are given due to dynamic pricing.

\begin{tabular}{|c|c|c|}
\hline Min $C^{\text {Total }}=\sum_{H H}$ & $\begin{array}{l}\sum_{t}\left[\left(E_{t, H H}^{H H, \text { baseload }}+\sum_{A p p l} E_{t, H H, A p p l}^{A p p l}\right.\right. \\
\left.\left.\left.\sum_{E V} E_{t, H H, E V}^{E V}\right) p_{t}\right]\right]\end{array}$ & 1 \\
\hline $\begin{array}{ll}\text { - } & \mathrm{C}^{\text {total }} \\
\text { - } & \mathrm{E}^{\mathrm{HH}, \text { baseload }} \\
\text { - } & \mathrm{E}^{\mathrm{EV}} \\
\text { - } & \mathrm{E}^{\mathrm{Appl}} \\
\text { - } & \mathrm{p} \\
\text { - } & \mathrm{t} \\
\text { - } & \mathrm{EV} \\
\text { - } & \mathrm{HH} \\
\text { - } & \mathrm{Appl}\end{array}$ & $\begin{array}{l}\text { Total electricity costs }[€] \\
\text { Base-load-demand of household }[\mathrm{kWh}] \\
\text { Electricity demand EV-charging }[\mathrm{kWh}] \\
\text { Electr. demand smart appliances }[\mathrm{kWh}] \\
\text { Electricity price }[€ / \mathrm{kWh}] \\
\text { Time unit } \\
\text { Electric vehicle } \\
\text { Household } \\
\text { Household appliance }\end{array}$ & \\
\hline
\end{tabular}

When looking at the electricity demand we used typical household loads for three different seasons (summer, winter, transition) and deducted the loads of the smart appliances (dishwasher, washing machine and tumble dryer) in order to 
model them separately. Additionally some households own $\mathrm{EV}$, if it is technically possible (meaning they can cover their mobility needs) and - depending on the scenario additionally economically feasible to them. Therefore a totalcost-of-ownership-calculation (TCO) for a purchasing decision in 2020 is done with four different vehicle categories (scooter, small car, medium-size car, large car) and two technologies (electric and conventional). The electricity demand of the EV is integrated by calculating the State-ofCharge (SoC) of each vehicle based on their mobility needs for every time-unit (15 minutes interval). The load-shifting potential of each charging process is only limited by the maximum and minimum boundary for SoC (cf. equation 2 ).

\begin{tabular}{|cll|}
\hline SoC $(t)=\operatorname{SoC}(t-1)+\left[E_{\text {charg }}(t)\right.$ & 2 \\
& $\left.-E_{\text {discharg }}(t)\right] / E_{\text {Bat }}$ & \\
\hline - & SoC & State-of-Charge [\%] \\
- & $\mathrm{E}_{\text {charg }}$ & Electricity demand EV-charging [kWh] \\
- & $\mathrm{E}_{\text {discharg }}$ & Electricity demand EV-riding [kWh] \\
- & $\mathrm{E}_{\text {Bat }}$ & Battery Capacity[kWh] \\
- & $\mathrm{t}$ & Time unit
\end{tabular}

By assuming rational-choice of households the loads of the smart appliances and the EV-charging are responsive to minimal changes in price. However, the full service has highest priority, meaning that the utility of the trip is higher than the possibly additional cost of charging at a high tariff. So in some cases battery-charging might take place even though the electricity price is comparably high, because the next trip has to be within reach. We assume that charging infrastructure is only used at home and not in public areas.

Table I provides an overview of the scenarios calculated for this paper. We include a RTP with three price levels and a high price spread $(7,22,37 \mathrm{ct} / \mathrm{kWh})$. The prices over the course of the modeled weeks (one week per season) have the same structure as the ones tested during the experimental studies. Although we don't see these extreme prices in the market yet, we included them for testing demand response under future conditions.

\begin{tabular}{|l|l|l|c|c|}
\multicolumn{4}{c}{ TABLE I. } & \multicolumn{1}{c|}{ MODELED SCENARIOS } \\
\hline \multirow{2}{*}{$\begin{array}{l}\text { Modelled } \\
\text { Scenarios }\end{array}$} & \multicolumn{1}{c|}{$\begin{array}{c}\text { Electricity } \\
\text { Pricing }\end{array}$} & $\begin{array}{c}\text { Parameters } \\
\text { Penetration }\end{array}$ & Season & Year \\
\cline { 2 - 5 } Scenario 1 & $\begin{array}{l}\text { Standard } \\
\text { tariff (22 } \\
\text { ct/kWh) }\end{array}$ & $\begin{array}{l}\text { a) technical } \\
\text { b) market- } \\
\text { based }\end{array}$ & Summer & 2020 \\
\hline Scenario 2 & $\begin{array}{l}\text { RTP (7, 22, } \\
37 \text { ct/kWh) }\end{array}$ & $\begin{array}{l}\text { a) technical } \\
\text { b) market- } \\
\text { based }\end{array}$ & Winter & 2020 \\
\hline
\end{tabular}

\section{B. Energy Smart Home Laboratory (ESHL)}

The ESHL on KIT campus represents a building of a $60 \mathrm{sqm}$ two-bedroom apartment for two residents, with an attached 20 sqm equipment room. A PV-system is installed on the roof and two e-scooters (Elmoto HR2) can be charged on plugs outside. The kitchen is equipped with smart appliances (washing machine, dish washer and tumble dryer) that are connected to a central communication gateway that provides data on the status of each appliance and is able to receive control signals. All appliances (smart and conventional) are monitored and integrated to the Energy Management System (EMS). Based on the electricity price information the EMS is able to schedule the smart appliances automatically at the most cost-effective time. Energy Management Panels (EMP) serve as human-machine-interface. It displays relevant information and actions of the EMS and is provided on touchscreen displays in each room and a mobile device (iPod Touch).

During three experimental phases, each with a duration between three to eight weeks, selected test-residents moved into the ESHL and experienced the technology and DRoptions on a daily basis for that period of time. During their residence we analyzed the effects of direct and indirect feedback, of different dynamic pricing models and automated load management on load-flexibility, i.e. ability to shift loads in time.

A screening questionnaire (during the recruiting process), a short standardized pre-post-questionnaire (on attitudes) and two in-depth interviews were conducted. Furthermore the test-residents were able to write about their experiences in an online blog. With the combination of these survey types we gained a rich amount of data in the participants' own words. This qualitative data was analyzed together with quantitative behavioral data from the real-time metering.

\section{RESUlTS}

In the following we present the results for both approaches separately before comparing them with each other.

\section{A. Modelling Results}

In a first scenario (1 a) a standard tariff is assumed - thus the households have no incentive to shift, but use the smart household appliances as usual and charge the EV immediately after arriving at home. We also assume a high EV-penetration rate exploiting the technically feasible potential of EV penetration. In this scenario an increase of peak-loads up to $231 \%$ is observed mainly due to EV-charging. This leads to an overall increase of the load-spread (cf. Fig. 1). The effect comes especially true in the evening hours. EV have both a higher load and electricity demand than any other single household appliance. When assuming a lower penetration rate (by exploiting just the economically feasible potential scenario $1 \mathrm{~b}$ ), an increase of load-peaks is observable as well however, not to the same extent (cf. Fig. 2). The maximum peak within the neighborhood lies around $330 \mathrm{~kW}$ with a market-based penetration and around $660 \mathrm{~kW}$ with a technical-based penetration. A first conclusion therefore is that with a higher share of EV the need for DR might increase.

Even though the three household appliances (washing machine, tumble dryer, dishwasher) have comparably lower demands than an EV, they are widely available in German households (e.g. $98 \%$ penetration of washing machines). Thus 


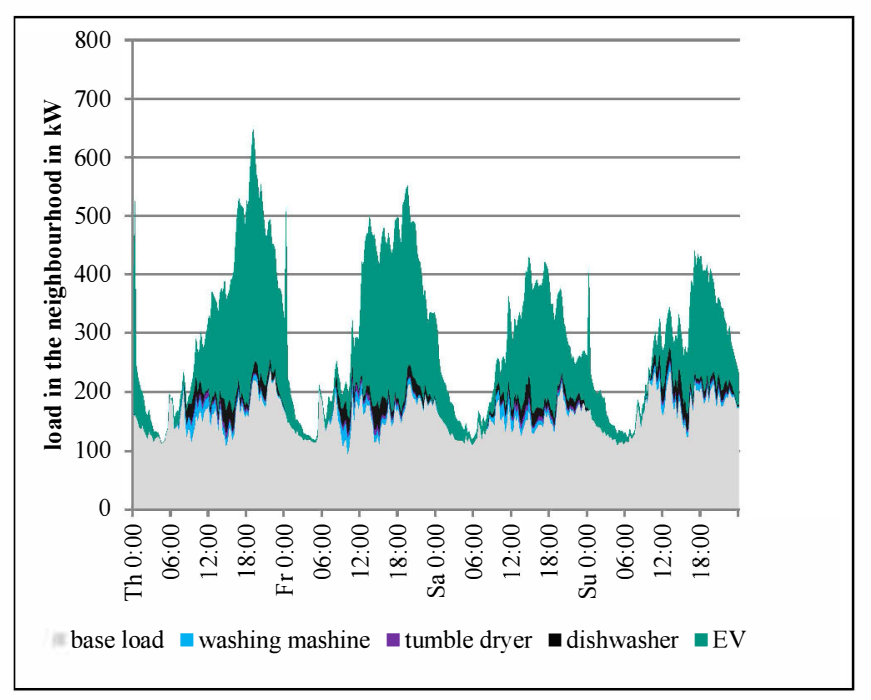

Figure 1. Scenario 1a: Effect of a high EV-penetration and uncontrolled charging on total loads (summer)

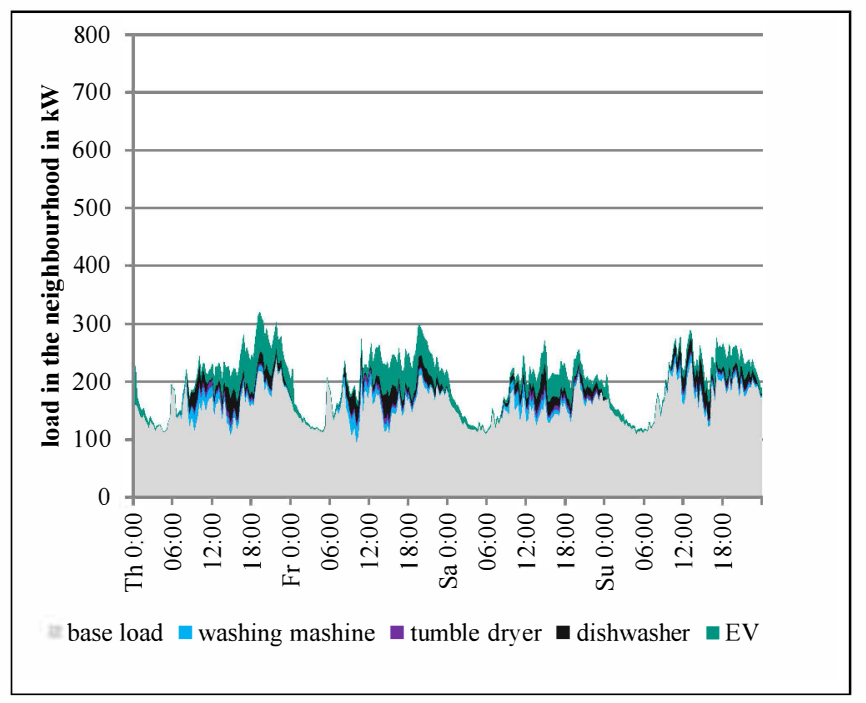

Figure 2. Scenario 1b: Effect of a market-based EV-penetration and uncontrolled charging on total loads (summer)

taking all appliances together their load-shifting potential might be interesting. After all their electricity demand $(\sim 3,700 \mathrm{kWh} /$ week $)$ equals the demand of $\mathrm{EV}$ in a marketbased scenario.

In the second scenario (2a) we assume a technical-based penetration of EV and a winter period because of generally higher load levels. Dynamic pricing is introduced. Fig. 3 shows that the pricing incentive leads to clear load-shifting effects. The households demand over $55 \%$ of electricity during low-price periods. The design of this pricing model leads to new and higher load-peaks $(885 \mathrm{~kW})$ as well as to a higher load-spread (cf. Table II). This effect however indicates that some loads are flexible enough to react to a pricing incentive.

Low-price time zones are well used for "pre-charging" the $\mathrm{EV}$ and overcoming longer high-price times. The long parking

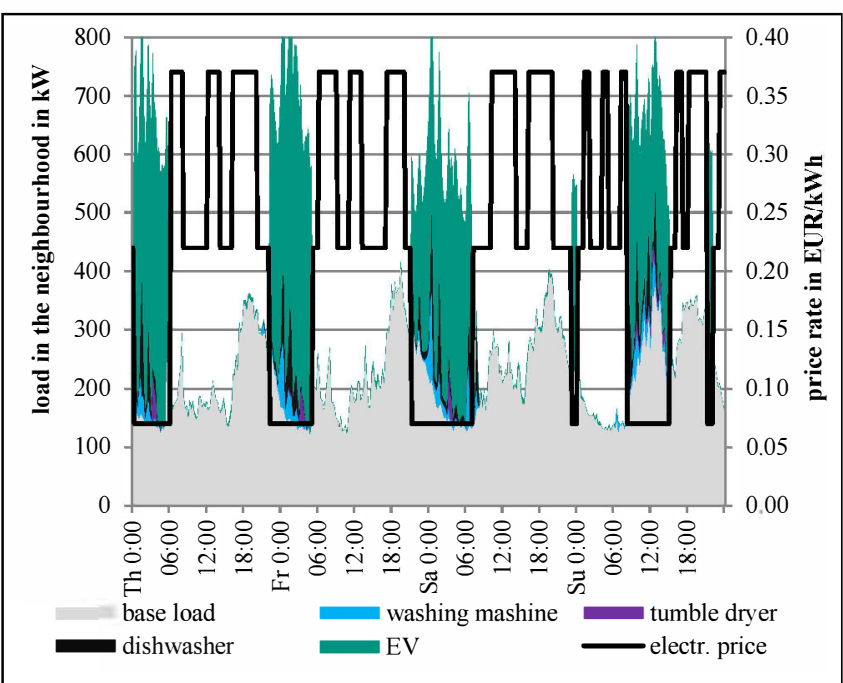

Figure 3. Scenario 2a: Effect of dynamic pricing on use of household appliances and EV-charging (winter)

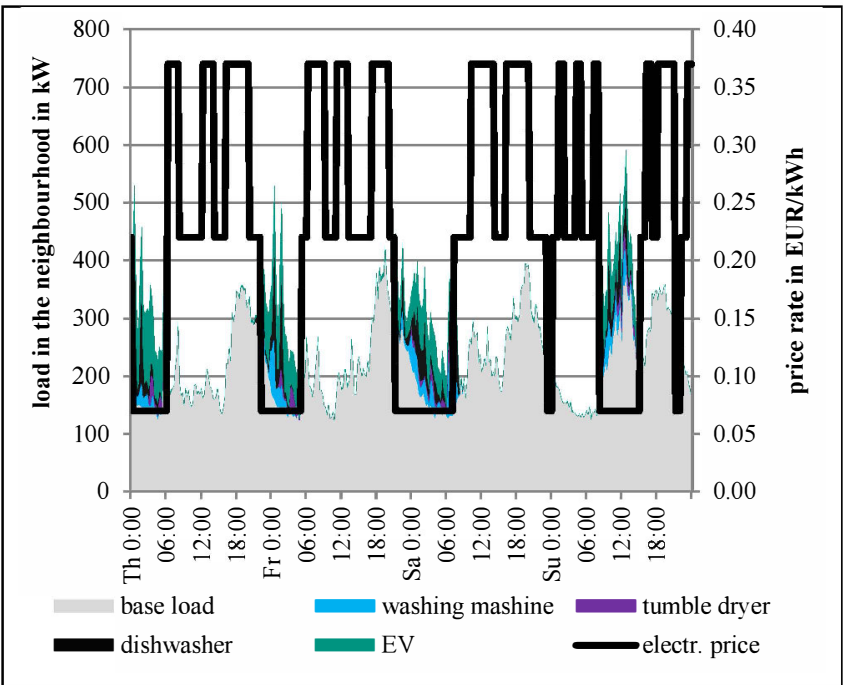

Figure 4. Scenario 2b: Effect of dynamic pricing on use of household appliances and EV-charging (winter)

hours of vehicles ensure high load flexibility without interfering with the mobility needs of the households. Over $99 \%$ of EV-charging takes place at low-priced times compared to $15 \%$ without price incentive. This leads on average to a $77 \%$ reduction in charging costs in this scenario. In total numbers the average household saves around 6 EUR/week on charging costs with the modeled RTP.

The effects are similar for smart household appliances. The dishwasher is used in $97 \%$ of the cases at low-priced times, the washing machine in $95 \%$ and the tumble dryer even in $100 \%$. Compared to conventional household appliances (that would not react to dynamic pricing) smart household appliances lead to similar relative savings as in the case of the EV - albeit the absolute terms are significantly higher. The average household in the modeled neighborhood pays 0.58 EUR instead of 1.75 EUR for the weekly use of these appliances. Whether the total savings can account for the 
investment into smart household appliances has to be discussed the same way as in the case for EV and smart charging stations - however, both aspects are out of scope of this paper.

The model-based analysis shows that there is theoretically a high load-shifting potential for EV-charging as well as for the use of smart household appliances. Dynamic pricing can exploit this potential - however, it is important to predict the effects on the total load level, as new load-peaks might result, which on the other hand could be a desired effect e. g. at windy times. If the households show enough flexibility in their electricity demand, load-shifting can lead to lower average costs without conserving electricity (cf. Table II).

TABLE II. EFFECTS ON LOADS AND PRICES (WINTER)

\begin{tabular}{|l|c|c|c|}
\hline $\begin{array}{c}\text { Effects on } \\
\text { loads and } \\
\text { prices }\end{array}$ & \multicolumn{3}{|c|}{ Parameters } \\
\cline { 2 - 4 } & $\begin{array}{c}\text { Max. Peak } \\
{[\boldsymbol{k} \boldsymbol{W}]}\end{array}$ & $\begin{array}{c}\text { Load-Spread } \\
(\text { Max/Min) }\end{array}$ & $\begin{array}{c}\text { Average price } \\
{[\text { ct/kWh] }}\end{array}$ \\
\hline Scenario 1a & 816 & 7.3 & 22 \\
\hline Scenario 1b & 499 & 4.5 & 22 \\
\hline Scenario 2a & 885 & 8.2 & 17.2 \\
\hline Scenario 2b & 591 & 5.7 & 21.1 \\
\hline
\end{tabular}

\section{B. Experimental Results}

While the model-based results in the section above demonstrate the theoretical potential of DR, the experimental results show how this potential is used by consumers in a realistic laboratory-setting. They can especially explain under which conditions this potential can be exploited and offer reasons-why.

When looking at all 13 experimental weeks across the different test-living-phases electricity was demanded at lowpriced times between $30 \%$ and $51 \%$. As different dynamic pricing models were tested during the phases, we can interpret a better reaction of the test-residents (i. e. higher share of electricity consumed during low price periods) with a higher acceptance of the pricing model. However, it has to be kept in mind, that real-user-behavior is hardly repeated, meaning that a variation in demand of up to $17 \%$ is observable even within the same test-living phase. Although the experimental phases are not fully comparable, because they were conducted during different seasons with different inhabitants, some general tendencies are still apparent:

- First of all, we observed that some "adaption" time is needed to fully understand the concept of dynamic pricing and to integrate DR into daily routines.

- A high number of price levels offers more possibilities to shift demand (also during the day), but carries the risk of entering the high-price time zones more often.
- The electricity price itself at each level was of less interest to the test-residents than the general level (low, medium, high).

- The time scheme influences the ability of the testresidents to shift appliance use. If low-price or midprice zones apply on the brink of a day, it is perceived as too early or too late as to comply with them.

"This weekend we were very flexible and thus tried to use the appliances at low-priced times. Only on Sunday evening the green zone started after 7 p.m. and we were not able to wait with cooking for our guests until that time. Let's see how we will manage during the week! For sure I will not get up before 6 a.m. to brew coffee with cheap electricity."

The main appliances shifted, according to the tested dynamic pricing models, were the ones also integrated in the optimization model and that were connected to the energy management system for automation: dishwasher, washing machine, tumble dryer and e-scooter-charging (cf. Fig. 5). All the other appliances were not shifted due to the immediate need of their service, such as light, cooking or TVentertainment. As an example the test-residents said to be able to postpone the dish-washer use by twelve hours without constraints in their daily routines. From their perspective the dish-washer was the most suitable, the coffee-machine and the stove the least suitable devices for subordinating to dynamic pricing. Furthermore they asked for a smart freezer that would automatically plan its cooling periods according to the prices and allow cost savings in a comfortable way.

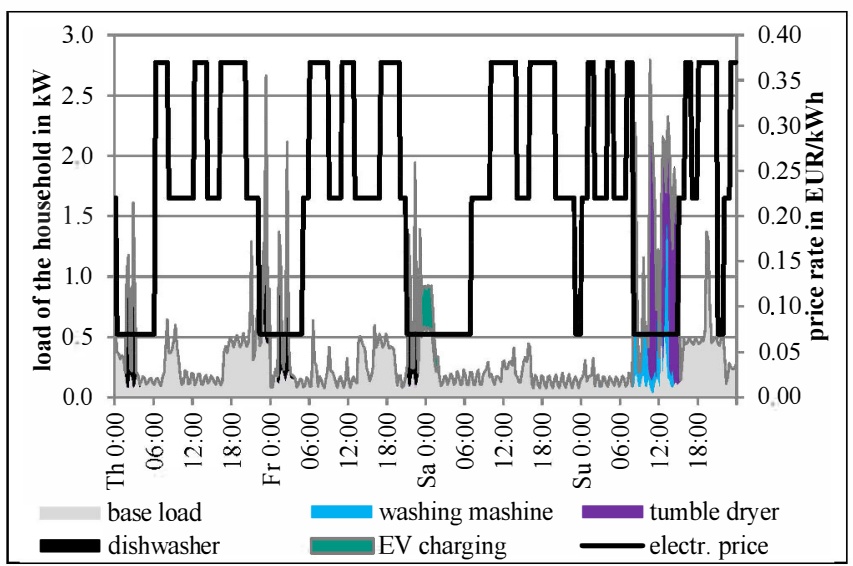

Figure 5. Electricity demand of a selected week during an experimental phase with dynamic pricing in the ESHL

An important motive for load-shifting has been the corresponding cost savings. The cost-saving expectation was fairly high (50 to $150 \mathrm{EUR} / \mathrm{year}$ ) compared to the projected savings from the experimental phases (20 to 60 EUR/year). Environmental issues were another important motive for the test-residents. The idea of being able to better integrate electricity generated by renewable resources into the system was especially appealing to them. Part of the participants' 
motivation for load-shifting was also due to the innovative setting in the ESHL.

For their own households cost savings would be the overriding motive for DR - especially together with smart household appliances that ensure more convenience in adapting dynamic pricing. However, the necessary investment costs are perceived as too high at the moment.

\section{Comparing the results of both analyses}

In order to better compare both analyses, we select one household of the modeled neighborhood with a similar demand structure and put the behavior of that household in relation to the laboratory results of the latest test-living phase. We analyze for both households a selected week during winter season. Fig. 6 visualizes that the reaction of the households are similar with regard to electricity demand. Compared to Fig. 5 a sensitive reaction to price spreads is observable at the same hours during the week in both cases.

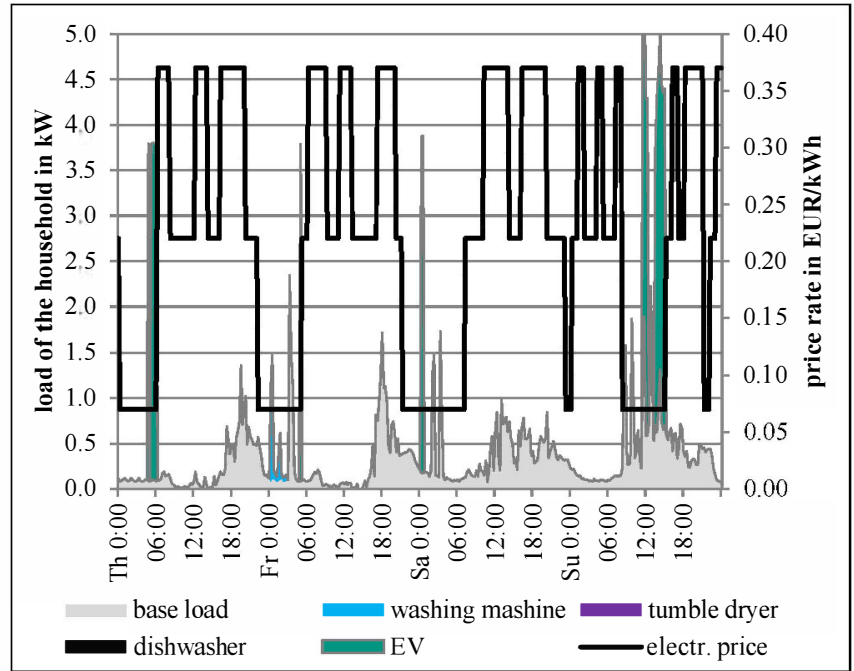

Figure 6. Electricity demand of a selected model-household with dynamic pricing during winter period

Tables III and IV show that a surprisingly high share of the load-shifting potential in the model can be exploited in the ESHL. While the rational-choice of the modeled household leads to an overall electricity demand of $60 \%$ at low-priced time - the test-residents demand $51 \%$ of electricity at the same times. The effect is even more obvious when looking at the single devices. While the modeled household uses the dishwasher in $100 \%$ of cases at $7 \mathrm{ct} / \mathrm{kWh}$-periods, the testresidents were able to shift $96 \%$ of the dishwasher-use into that price period. There are no differences for EV-charging both achieve to shift charging into low-price periods.

However, it has to be kept in mind, that the ESHL was equipped with e-scooters with lower energy demand than the electric cars in the model. This is also relevant, when comparing the cost savings in both analyses. While the testresidents saved $17 \%$ on electricity expenses with dynamic pricing in comparison to a standard rate, rational behavior of the modeled household leads to cost-savings of $32 \%$ per week.

The innovative setting of the ESHL as well as the high motivation of the test-residents lead to a high exploitation of the theoretical load-shifting potential and is close to rationalchoice. This is somewhat surprising with regard to potential barriers for DR such as stable daily routines, but supports the benefits of smart household appliances that ensure loadflexibility not only in the model, but also in daily life. These results should motivate further research to challenge this study with field tests outside of laboratory conditions. Cost-saving motives might then play an even greater role.

TABLE III. DEMAND OF MODELED HOUSEHOLD

\begin{tabular}{|l|c|c|c|c|c|}
\hline \multirow{2}{*}{ DS-Opt +} & \multicolumn{5}{|c|}{ Electricity Demand } \\
\cline { 2 - 6 } & $\begin{array}{c}\text { Total } \\
\text { house-hold }\end{array}$ & $\begin{array}{c}\boldsymbol{E V} \\
(\mathrm{car})\end{array}$ & Wash & Dry & Dish \\
\hline $7 \mathrm{ct} / \mathrm{kWh}$ & $51 \%$ & $100 \%$ & $99 \%$ & $96 \%$ & $96 \%$ \\
\hline $22 \mathrm{ct} / \mathrm{kWh}$ & $21 \%$ & $0 \%$ & $1 \%$ & $4 \%$ & $2 \%$ \\
\hline $37 \mathrm{ct} / \mathrm{kWh}$ & $28 \%$ & $0 \%$ & $0 \%$ & $0 \%$ & $2 \%$ \\
\hline $\begin{array}{l}\text { Electricity } \\
{[\mathrm{kWh}]}\end{array}$ & 72.7 & 1.4 & 5.6 & 11.0 & 8.6 \\
\hline
\end{tabular}

TABLE IV. DEMAND OF EXPERIMENTAL HOUSEHOLD

\begin{tabular}{|l|c|c|c|c|c|}
\hline \multirow{2}{*}{ ESHL } & \multicolumn{5}{|c|}{ Electricity Demand } \\
\cline { 2 - 6 } & $\begin{array}{c}\text { Total house- } \\
\text { hold }\end{array}$ & $\begin{array}{c}\text { EV } \\
\text { (scooter })\end{array}$ & Wash & Dry & Dish \\
\hline $7 \mathrm{ct} / \mathrm{kWh}$ & $60 \%$ & $100 \%$ & $99 \%$ & $100 \%$ & $100 \%$ \\
\hline $22 \mathrm{ct} / \mathrm{kWh}$ & $13 \%$ & $0 \%$ & $1 \%$ & $0 \%$ & $0 \%$ \\
\hline $37 \mathrm{ct} / \mathrm{kWh}$ & $27 \%$ & $0 \%$ & $0 \%$ & $0 \%$ & $0 \%$ \\
\hline $\begin{array}{l}\text { Electricity } \\
{[\mathrm{kWh}]}\end{array}$ & 78.8 & 21.6 & 3.6 & 3.6 & 7.8 \\
\hline
\end{tabular}

\section{DISCUSSION AND CONCLUSIONS}

We presented an interdisciplinary analysis of load-shifting potentials resulting from DR measures in private households. We analyzed dynamic pricing together with smart household appliances and smart charging. Therefore, we conducted two analyses and compared their results: (i) with an optimization model we calculated the techno-economical load-shifting potential assuming rational-choice of households in an urban neighborhood. In a smart home laboratory (ii) we then conducted experimental studies in order to observe the loadshifting potentials exploited by real-users under quasi-real conditions.

The optimization model shows that the need for DR increases with higher market penetration rates of EV. At the same time EV present a flexible load that is suitable for loadshifting. Under rational-choice as well as under experimental conditions the charging process of EV can be shifted in time by $100 \%$ without restrictions in mobility behavior - if households have an incentive to do so. 
Dynamic pricing shows effectiveness in activating this potential and leads to lower average electricity costs for the households. This is not only true for the charging process, but also for the use of the three household appliances under study (washing machine, tumble dryer, dishwasher). Due to high penetration of these appliances, but relatively low demand (compared to EV), their effectiveness for DR is higher as long as EV are not spread in many households.

Households could save around $77 \%$ of the electricity costs for the use of these appliances (including EV). A rough projection shows that the average household could save around $370 \mathrm{EUR} / \mathrm{year}$, which is higher than both the expectation of the test-residents (150 EUR/year) as well as the exploited savings during the experimental studies by them (up to $60 \mathrm{EUR} /$ year). There are two reasons: First of all most households in the DS-Opt+ Model own an electric car - only few have an electric two-wheeler, as in the experimental studies. As the electricity demand of the electric car is higher than of electric scooters, the cost savings are higher as well. The other reason is stability of load-shifting over time. While we compare selected weeks in this paper, it is difficult to predict the future behavior of real-users. However, the literature suggests, that demand automation together with smart appliances enables more stable load-shifting over time (cf. [26])

For further research it is thus important to evaluate the load-shifting potentials over time by analyzing long-term field experiments. It will then be interesting to calculate whether the realized cost savings account for the needed investment into smart home technologies. The integration of further devices of a future household (such as stationary battery systems) might positively influence this cost-benefitcalculation.

Cost-savings are possible due to price differences. More research is needed in the analysis on the exact effect of different dynamic pricing models on the behavior of households and thus on loads. Herding behavior might require further pricing elements, such as load-limits or power prices, which are widely common in the industrial sector (cf. [17]).

In order to exploit the theoretical load-shifting potential it is important to acquire high user acceptance for DR. Besides the cost-saving potentials and the design of dynamic pricing, it will also depend on the design of feedback options and the customer-friendliness of the technologies in use (cf. [26]).

\section{REFERENCES}

[1] BMWi: Eckpunkte für ein energiepolitisches Konzept. Report of the German Federal Ministry of Economics and Technology, Berlin Available:

http://www.bmwi.de/BMWi/Navigation/Energie/Energiepolitik/energie konzept,did=405004.html

[2] N. Hartmann, E.D. Özdemir. „Impact of different utilization scenarios of electric vehicles on the German grid in 2030", Journal of Power Sources 196(4), 2311-2318, 2010

[3] P. Fox-Penner, Smart Power, Climate Change, the Smart Grid, and the Future of Electric Utilities. Washington, DC: Island Press, 2009.

[4] IEEE Smart Grid "Power Systems of the future: the Case for Energy Storage, Distributed Generation, and Microgrids." November 2012
[5] C. Ahn, C.T. Li, and H. Peng. Optimal decentralized charging control algorithm for electrified vehicles connected to smart grid, Journal of Power Sources 196(23), 10369-10379, 2011

[6] L. G. Swan and V. I. Ugursal, V. I. "Modeling of end-use energy consumption in the residential sector: A review of modeling techniques", Renewable and Sustainable Energy Reviews, 13(8): 18191835,2009

[7] M. Klobasa, "Dynamische Simulation eines Lastmanagements und Integration von Windenergie in ein Elektrizitätsnetz", Ph.D dissertation, Universität Karlsruhe, 2009.

[8] K. Clement-Nyns, E. Haesen, and J. Driesen. "The Impact of Charging Plug-In Hybrid Electric Vehicles on a Residential Distribution Grid" IEEE Transactions on Power Systems 25(1), 371-380, 2010

[9] S. Gottwalt, W. Ketter, C. Block, J. Collins, and C. Weinhardt, "Demand side management: A simulation of household behavior under variable prices". Energy Policy, 39 (12), 8163-8174, 2011.

[10] T. Blank, W. Mauch, T. Mezger, and U. Wagner, „Zusätzlicher Energie und Leistungsbedarf für Elektrostraßenfahrzeuge.“ Energiewirtschaftliche Tagesfragen 58 (12):50-52, 2008.

[11] C. Leitinger and M. Litzlbauer, „Netzintegration und Ladestrategien der Elektromobilität“. Elektrotechnik und Informationstechnik 128 (12): 10-15, 2011

[12] T. Pollok, C. Matrose, T. Dederichs, A. Schnettler, E. Szczechowicz "Classification and Comparison of Multi Agent Based Control Stratefies for Electric Vehicles in Distribution Networks", in Proc. 21st International Conference and Exhibition on Electricity Distribution (CIRED), 2011

[13] S. Shao, M. Pipattanasomporn, and S. Rahman, "Challenges of PHEV penetration to the residential distribution network". IEEE PES General Meeting 1-8, 2009.

[14] G. Brauner $\mathrm{G}$, „Energiebereitstellung für die Elektromobilität" Elektrotechnik und Informationstechnik 126 (10):371-374, 2009.

[15] C. Leitinger, M. Litzlbauer, A. Schuster, G. Brauner, D. Simic, G. Hiller et al. „Smart Electric Mobility - Speichereinsatz für regenerative electrische Mobilität und Netzstabilität". Report, Austria 2011.

[16] G. Nischler, C. Gutschi, M. Beermann, and H. Stigler, „Auswirkungen von Elektromobilität auf das Energiesystem". $e \& i$ Elektrotechnik und Informationstechnik 128 (1-2):53-57, 2011

[17] T. Kaschub, A.-G. Paetz, P. Jochem, and W. Fichtner „Lastmanagement mit intelligenten Haushaltsgeräten und Elektrofahrzeugen - eine modellgestützte Analyse“" in Proc. 2012 VDE Kongress.

[18] J. Stromback, C. Dromacque, and M. H. Yassin, "The potential of smart meter enabled programs to increase energy and system efficiency - a mass pilot comparison". VaasaETT Global Energy Think Tank 2011.

[19] A.-G. Paetz, E. Dütschke, and W. Fichtner, "Smart Homes as a Means to Sustainable Energy Consumption: A Study of Consumer Perceptions", Journal of Consumer Policy, Volume 35, Issue 1 (2012), 23-41, 2012

[20] Charles River Associates, Primer on Demand-Side Management Report for the World Bank. Oakland 2005.

[21] A.-G. Paetz, E. Dütschke, and A. Schäfer, „Die Last mit der Lastkontrolle" Energie \& Management, 12/2011, 19, 2011.

[22] A.-G. Paetz, P. Jochem, and W. Fichtner, „Demand Side Management mit Elektrofahrzeugen - Ausgestaltungsmöglichkeiten und Nutzerakzeptanz", in: Proc 12. Symposium Energieinnovation 2012

[23] A.-G. Paetz, M. Pfriem, P. Jochem, W. Fichtner, and F. Gauterin, "Smart Charging - Results from an On-Road Test with Electric Scooters", in: Proc. 12th IAEE European Energy Conference Proceedings 2012.

[24] Das deutsche Mobilitätspanel (MoP) - Erhebungen der Jahre 1997 bis 2009. Hg. v. Institut für Verkehrswesen, Karlsruher Institut für Technologie.

[25] P. Hebes, S. Trommer, and A. Kihm, Elektromobilität: Analyse des Marktpotentials in verschiedenen Raumtypen. DLR - Institut für Verkehrsforschung, Berlin, 2011.

[26] A.-G. Paetz, T. Kaschub, P. Jochem, and W. Fichtner, "Testing Demand Response with Smart Homes and Electric Scooters", in: Proc. ACEEE 2012 Summer Study. 